\title{
The Use of Geochemical Methods to Characterize the Metamorphic Domain in the Belgian Ardennes
}

\author{
F. SONDAG ${ }^{1}$ and J.C. DUCHESNE ${ }^{2}$ \\ ${ }^{l}$ Laboratoires de Géologie Générale, Place Pasteur 3, B-1348 Louvain-la-Neuve, Belgium \\ ${ }^{2}$ Laboratoires Associés de Géologie, Pétrologie et Géochimie, Université de Liège, B-4000 Sart-Tilman, Belgium
}

\begin{abstract}
In the Belgian Ardennes anticline, low-grade metamorphism has locally affected the siltopelitic Lower Devonian formations. In the metamorphic domain, the Ti content of stream sediments is very high $(>0.17 \%)$, giving rise to a widespread regional Ti anomaly. This anomaly faithfully follows the limits of the metamorphic external zone proposed by Beugnies (1986). This is due to the appearance of ilmenite in the metamorphosed rocks and its subsequent concentration in the stream sediments. A statistical study of major- and trace-element contents of rocks sampled outside the metamorphic domain indicates a strong correlation between $\mathrm{Ti}$ and $\mathrm{Al}, \mathrm{K}$ and $\mathrm{Rb}$, suggesting that the Ti content is related to the illite content of the samples. Ti is therefore washed away with the clay fraction in the weathering process leading to stream sediment formation. Indeed, outside the metamorphic area, $\mathrm{Ti}$ is not involved in the main factors governing trace-element distribution in the stream sediments. The use of stream sediment geochemical prospecting provides a confirmation of petrological and structural work and may thus help in the accurate mapping of metamorphism limits.
\end{abstract}

\section{INTRODUCTION}

The Belgian Ardennes anticline of Lower Devonian age (Gedinnian, Siegenian, Emsian) is made up of Paleozoic detrital sediments, essentially silt and pelite, with a total thickness of 6-7 km. It separates the Dinant Synclinorium in the north from the Neufchateau-Eifel Synclinorium in the south. These formations lie unconformably on the Cambrian of the Caledonian basement (Fig. 1). This domain of uniform lithologie composition was affected during the Variscan orogeny by a low-pressure, low- to moderate-temperature metamorphism older than the main Variscan deformation. A detailed map illustrating the metamorphic isograds has recently been drawn by Beugnies (1986) on the basis of the mineral parageneses. This author has shown that ilmenite can be used as an index mineral characterizing the metamorphic domain.

In addition to these petrological and structural studies, two geochemical approaches provided new data on the Ardennes. The first is part of a geochemical stream sediment survey undertaken at the University of Louvain (Sondag, 1985). The second is a systematic lithogeochemical inventory of Lower Devonian rocks initiated by one of the authors (J.C.D.) at the University of Liège.

Both approaches lead to a remarkably consistent picture. In particular, the Ti content of the stream sediments can be used to delimit the boundary of the metamorphic domain. The purpose of this paper is to present the geochemical data and the methods which allow the unraveling and discussion of the behaviour of Ti inside and outside of the metamorphic domain. 
Published in: Journal of Geochemical Exploration (1987), vol. 27, pp. 311-321. Status : Postprint (Author's Version)

Fig. 1. Geological map of Central Ardennes Anticline (geological boundaries according to Asselberghs, 1946).

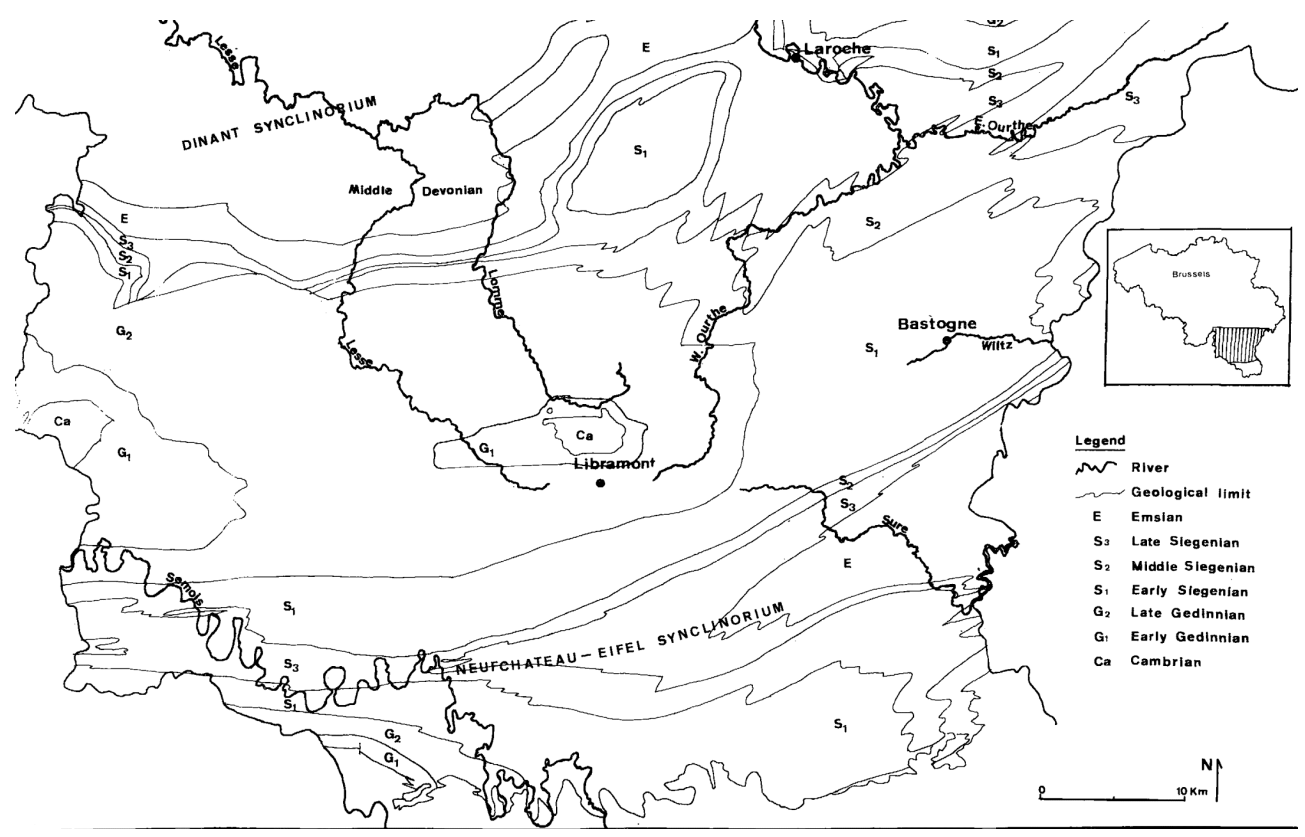




\section{REGIONAL TITANIUM ANOMALY IN STREAM SEDIMENTS}

The analysis of 3141 stream sediments (for analytical methods, see Appendix), collected over an area of about $3000 \mathrm{~km}^{2}$ underlain by Lower Devonian rocks, demonstrated that Ti has a log-normal bimodal distribution. The inflexion point separating the two modes at $1700 \mathrm{ppm}$ was retained as the regional threshold.

The geographical distribution of these two populations illustrates the strong regional correlation of the Tianomalous stream sediment samples with the metamorphic domain (Fig. 2). The illustrated limit of the metamorphic domain corresponds with the first appearance of ilmenite (and rutile) in pelite as drawn by Beugnies (1986).

We wish to show that this anomaly is related to a change in Ti behaviour during weathering and transportation in response to the appearance of metamorphic Ti minerals, particularly ilmenite, in rocks.

\section{TITANIUM IN WHOLE ROCKS}

Forty-five rock samples coming from the Ourthe valley outside the metamorphic domain near Laroche (Fig. 1) were analyzed (see Appendix) for major and trace elements (Meus, 1984). They belong to the various lithological units of Lower Devonian age (Gedinnian, Siegenian and Emsian, according to Asselberghs, 1946). The samples consist of $16 \%$ sandstone, $40 \%$ siltstone and $44 \%$ pelite.

Ti is strongly correlated with $\mathrm{Al}(r=0.92), \mathrm{K}(0.89)$ and $\mathrm{Rb}(0.87)$; this suggests that variations of the Ti content are mainly controlled by the quantity of illite of the rock. Although it could be present in the lattice of this mineral in substitution for Al in octahedral sites (Correns, 1976), the presence of very small rutile needles in illite, possibly resulting from post-depositional recrystallisation, has also been locally observed (A. Beugnies, pers. commun., 1986). A R-mode principal component analysis (PCA) of the chemical data shows (Fig. 3) that $\mathrm{Ti}$ is playing a role in the two most important factors, F1 and F2, which account for more than 55\% of the total variance. The first factor, positively loaded with $\mathrm{Si}, \mathrm{Zr}$ and $\mathrm{Cr}$ and negatively with all other elements, may be interpreted as a sorting factor or quartz-dilution factor. It represents the resistate minerals (quartz, zircon and chromite) relative to other detrital minerals (illite, chlorite, carbonates). F2 is the illite/(chlorite+carbonate) factor for it opposes the elements commonly found in illite $(\mathrm{K}, \mathrm{Rb}, \mathrm{Al}, \mathrm{Ti}, \mathrm{Ba}$ and possibly $\mathrm{Na})$ to those forming chlorite and carbonate $(\mathrm{Ca}, \mathrm{Mg}, \mathrm{Mn}, \mathrm{FeO})$. It can thus be suggested: (1) that Ti does not occur significantly in minerals such as ilmenite, commonly found in paleoplacers associated with zircon and other resistate minerals (Calvert, 1976) ; and (2) that it is mainly controlled by the illite fraction. This behaviour does not appear to depend upon the regional variations. Indeed in the southern part of the Dinant Synclinorium, the study of several series of samples from various localities in the same formations basically shows the same factors and factor loadings (Wilmart, 1984).

It can be concluded that beside the fact that ilmenite and other Ti-rich minerals do not contribute significantly to the Ti content of the unmetamorphosed rocks, the strong association of Ti with the illite component suggests that this element was brought into the basin as a minor element with the detrital illite and that this association was preserved during diagenesis.

Moreover, samples taken from inside the metamorphic area have a Ti content not significantly higher than outside the area. The relationship between $\mathrm{Ti}$ and the $\mathrm{Al}-\mathrm{K}-\mathrm{Rb}$ group remains the same (correlation coefficients ranging from 0.65 to 0.87 ) despite the fact that mineralogical changes involving those elements are conspicuous: formation of ilmenite, rutile, muscovite and pyro-phyllite (Beugnies, 1986). This is a fair indication that the metamorphic regime was isochemical and that the distribution of elements prevailing at the end of diagenesis was preserved during metamorphism. The fact that the limit of the metamorphic domain cuts across the various lithological formations is also in favour of an isochemical process. 
Published in: Journal of Geochemical Exploration (1987), vol. 27, pp. 311-321. Status : Postprint (Author's Version)

Fig. 2. Map of Ti distribution in stream sediment samples over the Lower Devonian. The line shows the limit of metamorphic domain according to Beugnies (1986)

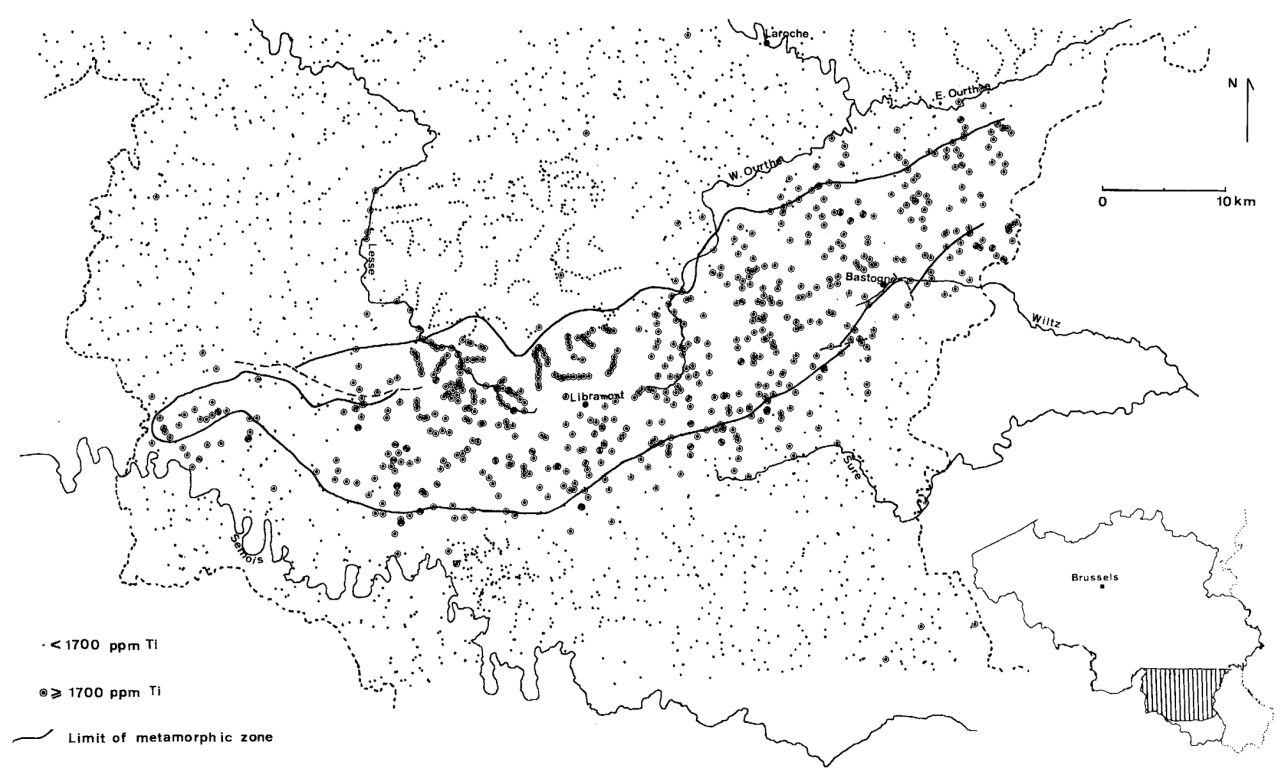


Fig. 3. Element loadings of principal component analysis of whole rock geochemical data from Laroche area $(n=49)$.

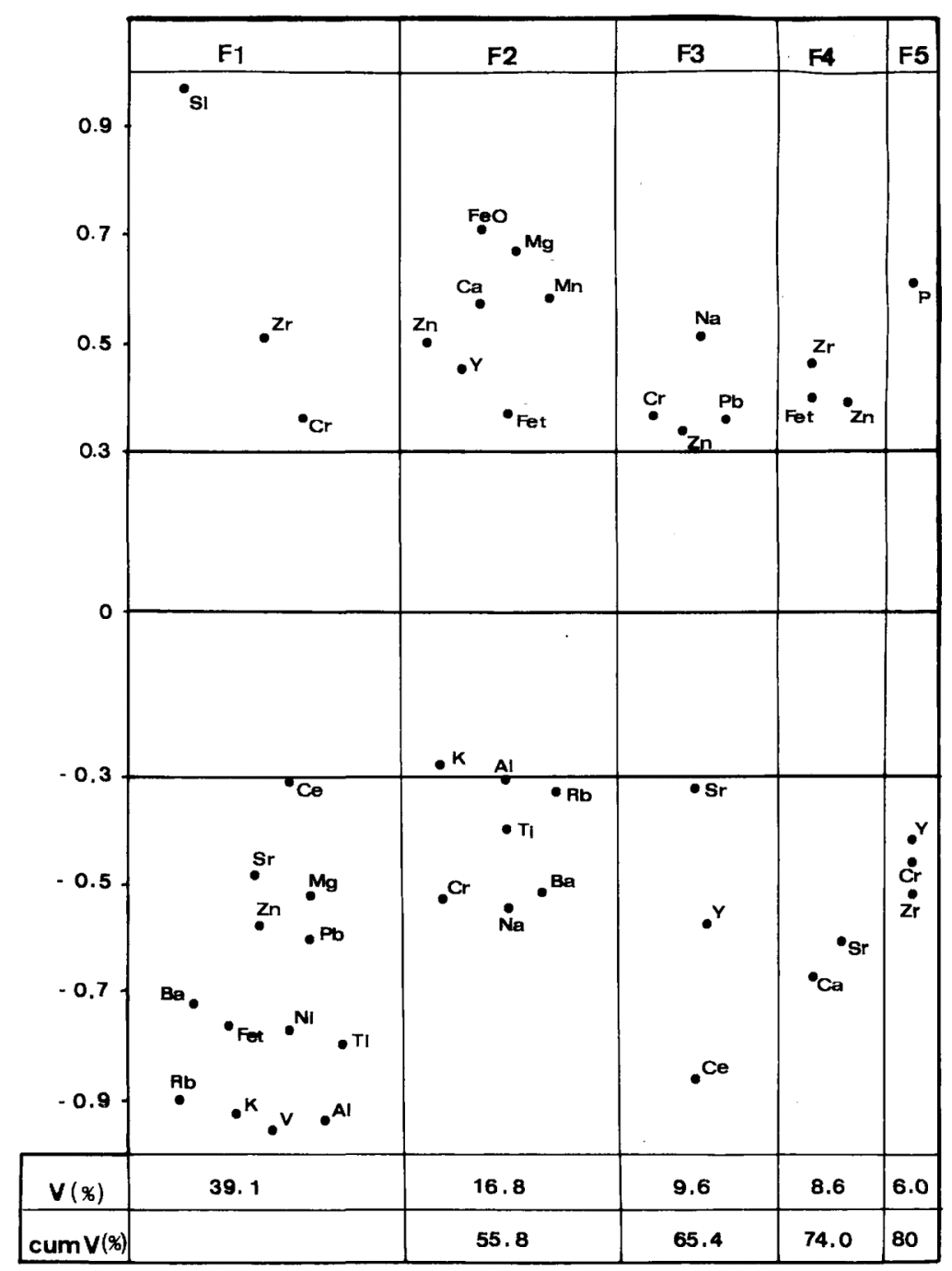

\section{TITANIUM IN STREAM SEDIMENTS}

The geochemical association of $\mathrm{Ti}$ with illite can be used to predict that Ti will follow the fine-grained fraction during weathering and transportation processes. This view is indeed supported by the statistical study of 95 stream sediment samples coming from the surroundings of Laroche, in an unmetamorphosed area, using a principal component analysis (Fig. 4). About $80 \%$ of the total variance is explained with 4 factors. The first factor groups transition elements such as $\mathrm{Cu}, \mathrm{As}, \mathrm{Ni}, \mathrm{V}$. This association has already been shown by Lecomte and Sondag (1980) to be related to Fe and/or Mn oxi-hydroxides in the surface environment. The second factor associates the three analyzed REE ( $\mathrm{La}, \mathrm{Y}$ and $\mathrm{Ce}$ ) with $\mathrm{Sr}$ and $\mathrm{Ba}$. These last two elements suggest an influence of clays while the grouping of the REE could be related to the presence of residual minerals such as zircon, monazite or other phosphates. Factor 3 shows the affinity of some elements for the Mn oxi-hydroxide phase. These factors explain about $20 \%$ of the data variance each and Ti does not significantly contribute to any of them. In fact, Ti only plays a role in F4 where it is opposed to $\mathrm{Ce}, \mathrm{Ni}$ and $\mathrm{U}$. The contribution of this fourth factor is, however, rather small $(12 \%)$.

A contrast in the behaviour of Ti appears in stream sediment from inside the metamorphic domain, south of the Laroche area between Bastogne and Libramont. Results of PCA on 99 samples indicate (Fig. 5) that F1 associates $\mathrm{Fe}$ with transition elements, and that the latter are strongly opposed to $\mathrm{Ti}$, and to a lesser extent to $\mathrm{Nb}$. This factor explains more than one third of the total variance and nearly half of the variance accounted for by the 
first four factors. Factors 2 and 3 appear very similar to F3 and F2 determined from the samples taken outside the metamorphic domain.

Fig. 4. Element loadings of PCA for stream sediment geochemical data outside the metamorphic domain, Laroche area $(n=95)$.

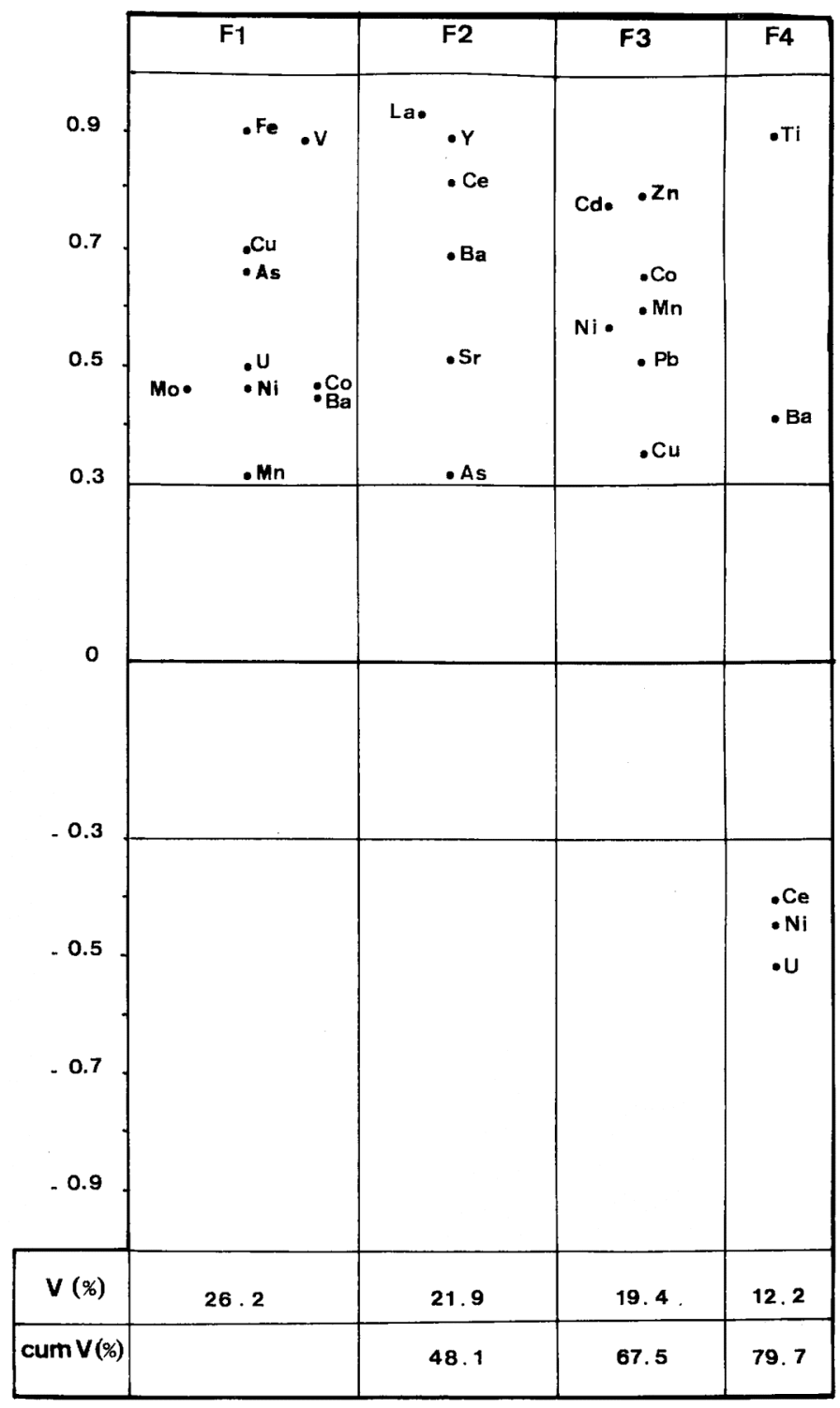


Fig. 5. Element loadings of PCA for stream sediment geochemical data in the metamorphic domain $(n=99)$.

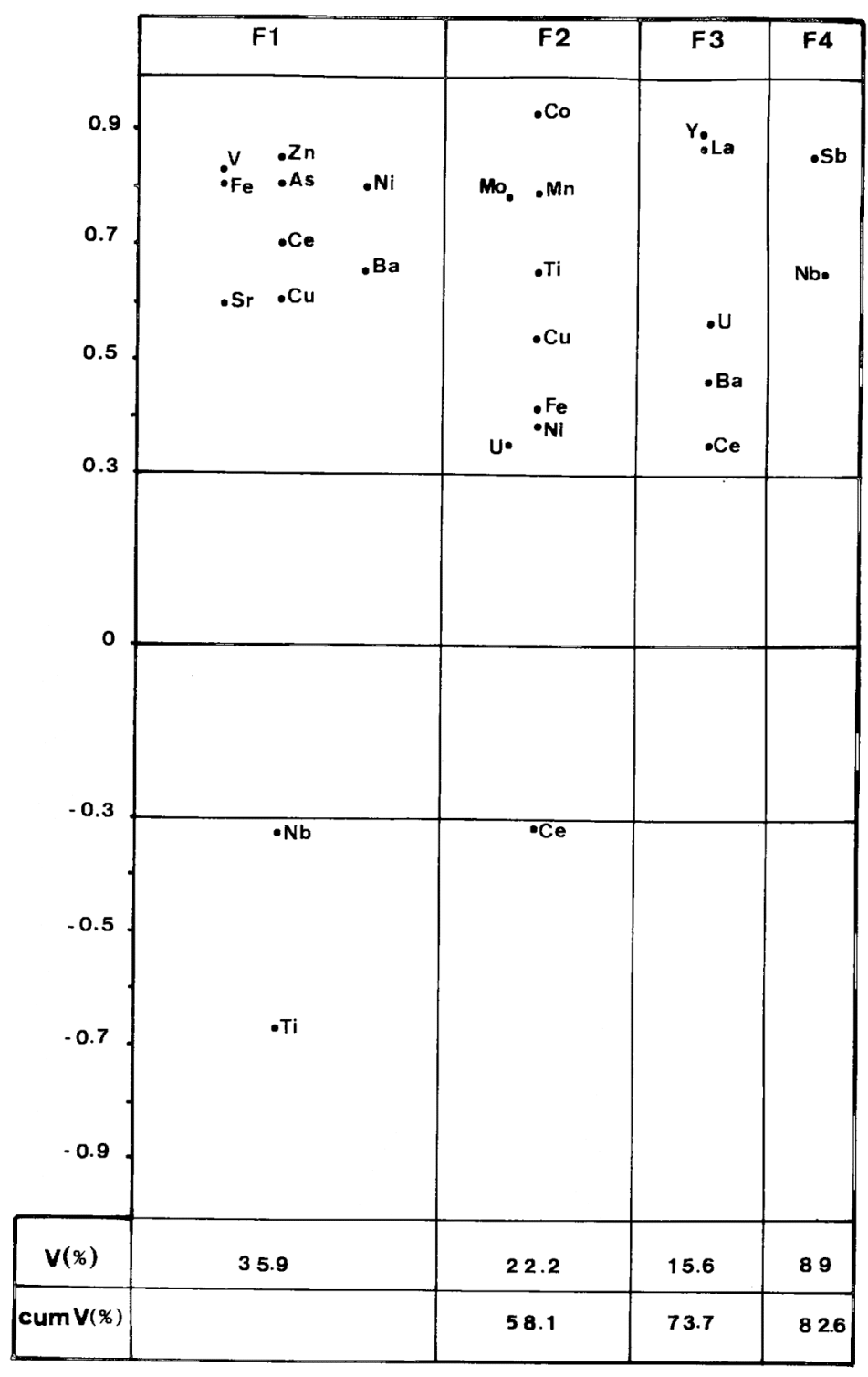

This strong opposition of Ti against the other elements can be explained by the presence of ilmenite and other Ti-minerals in the stream sediments. Mineral separations carried out on two Ti-rich stream sediment samples (> $0.6 \%$ ) have indeed revealed the presence of up to $9 \mathrm{wt} . \%$ ilmenite in the -80 -mesh fraction. Besides ilmenite, some anatase (ca. 0.2 wt.\%) and traces of titanite were also identified by X-ray diffraction (A.M. Fransolet, pers. commun., 1986). All these minerals together with some zircon (0.01-0.05 wt.\% ) constitute the bulk of the heavy mineral fraction $(\mathrm{D}>3.3)$. Ilmenite, which is a resistate heavy mineral, can be concentrated in the sediments of the streams which flow relatively fast so that clays and lighter minerals are washed away. This concentration leads to the broad regional anomaly in Ti. Outside the metamorphic domain, the Ti content drops drastically because $\mathrm{Ti}$ follows the clay fraction, which is considerably diluted by quartz. The clay content in stream sediments rarely exceeds $20 \%$; assuming a value of $0.3-0.5 \%$ for $\mathrm{Ti}$ in the clay leads to a background of 600 $1000 \mathrm{ppm}$, consistent with the observed distribution.

An interesting inference is the limited mobility of ilmenite which remains near its source. Indeed a detailed study of the map (Fig. 2) indicates only very few discrepancies between the Ti-anomalous zone and the limit proposed by Beugnies (1986). In some areas however, anomalous values are found outside of the limits of the metamorphic domain. This may result from downstream transport especially in the steeper valleys, near the Ourthe, Sure, Lesse and Semois rivers. This is particularly obvious along the Lesse river, which is the only major 
river sampled, in which samples with more than $1700 \mathrm{ppm}$ Ti exist $15 \mathrm{~km}$ downstream from the limit of the metamorphic domain. East of Bas-togne, on the other hand, samples with high Ti occur over an area which cannot be completely explained by downstream transport when looking at the drainage pattern. This could indicate an extension of the metamorphic domain. In the west, there is a lack of Ti anomalies in the metamorphic domain. This corresponds to the Middle Gedinnian formation G2a ("Oignies" formation) of a chemical composition inadequate to produce metamorphic ilmenite (Beugnies, 1986).

\section{CONCLUSIONS}

In the metamorphic area, $\mathrm{Ti}$ in stream sediment occurs mainly in $\mathrm{Ti}$ oxides of which ilmenite is the most common. This is due to the formation of ilmenite in rocks of appropriate chemical composition. The resistate nature of ilmenite and its high density allow its concentration in stream sediments not far from the source rocks.

Outside the metamorphic domain, Ti in rocks is basically controlled by the behaviour of illite of either detrital or epigenetic origin. During weathering processes Ti remains linked to the clay minerals. Since the clay fraction generally represents only $10-20 \%$ of the stream sediment samples, its Ti content is relatively low $(<1700 \mathrm{ppm})$ and shows little variation.

The uniform silt and pelite composition of the rocks over the entire area is a favourable factor in the development of Ti-rich stream sediments. The correspondence of this area with the metamorphic isograd confirms the careful geological field observations of Beugnies and suggests that stream sediment geochemistry could be used elsewhere for facilitating the mapping of such metamorphic zoning.

\section{ACKNOWLEDGEMENTS}

The stream sediment survey has been carried out under contract No. 141-24 (Prof. H. Martin leading) with the Ministry of the Région Wallonne. Mr. A. Liénard, Ministre de l'Aménagement du Territoire, de la Vie Rurale, de l'Eau et du Sous-sol pour la Région Wallonne and Ir. Ch. Frenay, Director of the Service Ressources Sous-sol have authorized the use of the stream sediment data. The whole rock data were obtained in program no. 112 of the Belgian Fund for Joint Basic Research (Ministerial Initiative) to Prof. J.C. Duchesne. Dr. A.M. Fransolet has identified trace amounts of some minerals. The authors are greatly indebted to Prof. A. Beugnies for his constructive comments on the results and to Dr. A. Armour-Brown for improving an early version of the manuscript.

\section{APPENDIX}

\section{Analytical methods}

Rock analysis

Major elements were determined by X-ray fluorescence (XRF) on Li-borate glass discs. Na and trace elements ( $\mathrm{Ba}, \mathrm{Ce}, \mathrm{Co}, \mathrm{Cr}, \mathrm{Mn}, \mathrm{Nb}, \mathrm{Ni}, \mathrm{Pb}, \mathrm{Rb}, \mathrm{Sr}, \mathrm{Ti}, \mathrm{V}, \mathrm{Y}, \mathrm{Zn}$ and $\mathrm{Zr}$ ) were analyzed from pressed powder pellets by $\mathrm{XRF}$ and matrix corrections were made using the major element composition.

\section{Stream sediment analysis}

After drying at $60{ }^{\circ} \mathrm{C}$ for $48 \mathrm{~h}$ the samples were sieved and the -80 -mesh fraction was retained. A hot $\left(120^{\circ} \mathrm{C}\right)$ $\mathrm{HCl}-\mathrm{HNO}_{3}$ - $\mathrm{HF}(8,5$ and $2.5 \mathrm{ml}$, respectively) attack was performed on $2.5 \mathrm{~g}$ of sample. The acid mixture was evaporated to dryness, the residue was re-dissolved with $10 \mathrm{~mL} 4 N \mathrm{HNO}_{3}$ and diluted to $50 \mathrm{~mL}$ in a volumetric flask. After centrifugation, the solutions were analyzed by solid fluorimetry for $\mathrm{U}$ and by direct current plasma emission spectrometry for Mn, Zn, As, Cd, Sb, Ti, Fe, Ni, Cu, Mo, Co, Nb, Y, Pb, La, V, Sr, Ba, Ce and Ag.

\section{REFERENCES}

Asselberghs, E., 1946. L'Eodévonien de l'Ardenne et des régions voisines. Mém. Inst. Géol. Univ. Louvain, $14,423 \mathrm{pp}$.

Beugnies, A., 1986. Le métamorphisme de l'aire anticlinale de l'Ardenne. Hercynica, II ( 1 ) : 17-33.

Calvert, S.E., 1976. The mineralogy and geochemistry of near-shore sediments. In: J.P. Riley and R. Chester 
(Editors), Chemical Oceanography. Academic Press, London, pp. 187-280.

Correns, C.W., 1976. Titanium. In: K.H. Wedepohl (Editor), Handbook of Geochemistry, II-2. Springer, Berlin, pp. B1-O17.

Lecomte, P. and Sondag, F., 1980. Regional geochemical reconnaissance in the Belgian Ardennes: secondary dispersion patterns in stream sediments. Mineral. Deposita, 15:47-60.

Meus, P., 1984. Etude pétrographique et géochimique du Dévonien inférieur à Laroche et Couvin. Licence Thesis, Faculty of Sciences, Univ. Liège, 81 pp. (unpubl.).

Sondag, F., 1985. Geochemical inventory in the stream sediments over the Paleozoic formations of Belgium. Bull. Soc. Belge Géol., Paléontol., Hydrol., 94:159-163.

Wilmart, E., 1984. Modelée géochimique des sédiments paléozoïques du Sud de la Belgique. Final Rep. Program No. 112 to the F.R.F.C., 318 pp. (unpubl.). 